\title{
Drug Incompatibilities in a Hospital Setting
}

\author{
Youssef Moutaouakkil*, Badr Adouani, Rachid el Jaoudi, Yahia Cherrah and Yassir Bousliman \\ Laboratory of Pharmacology-Toxicology, Faculty of Medicine and Pharmacy, University Mohamed V, Morocco
}

Submission: February 02, 2018; Published: April 25, 2018

*Corresponding author: Youssef Moutaouakkil, Laboratory of Pharmacology-Toxicology, Faculty of Medicine and Pharmacy, Rabat Institute, University Mohamed V, Morocco, Tel: +2126 79271669; Email: youssefmoutaouakkil@yahoo.com

Summary

Physicochemical drug incompatibilities are a frequent problem in hospital environment, because of the number of drugs perfused by the central catheters. Several factors modify the risk of physicochemical incompatibilities: concentration, contact time, $\mathrm{pH}$, type of solvent used, temperature, light. There are a number of practical measures to reduce the risk, such as sequential drug administration, use of compatibility chart, and use of all catheter lumens. Pharmacists' participation in drug administration is the best answer.

Keywords: Drug Incompatibilities; Care Units; Hospital

\section{Introduction}

In hospitals and especially in intensive care units, most drugs are administered intravenously for several reasons: (it is an emergency: fast, intubated patients, difficulty of access to the digestive tract). The infusion of the drugs is done by an element called catheter has a limited number of lights, several drugs pass on the same light where comes the problem of the drug incompatibility. Drug incompatibilities occur before drugs reach the patient, in an infusion line, resulting from physicochemical reactions between several drugs, between drug / solvents, drug / adjuvants, or with the equipment used. Drug incompatibility reactions depend on drug concentration and contact time between drugs [1]. The present work makes it possible to put the point on the essential points with regard to incompatibilities in hospital.

\section{Drug incompatibilities}

\section{Risk factors}

During Y-infusion in a critical care setting, two risk factors responsible for incompatibility [2]:

a) Administration of undiluted substances.

b) Use of an extension between the infusion lines and the patient.

\section{Types of incompatibilities}

The physico-chemical incompatibility can take place between 2 active ingredients, between an active ingredient and a solvent or an ion.

The physico-chemical incompatibility is manifested by: a) Visible change: Color change, gas release, formation of a precipitate or crystals, cloudiness.

b) Invisible change: $\mathrm{PH}$ change, formation of toxic products, decrease in the concentration of active ingredient.

Physical incompatibilities: Visually translated by the change of a physical state Lead to the formation of a precipitate, obstruction of catheters, vinous irritations, pulmonary or renal embolism. Maybe reversible, depends on the concentration of products. Reaction type: acid-base / complexation / formation of poorly soluble salts.

Chemical incompatibilities: Resulting in the phenomenon of degradation, it is the result of continuous chemical reactions, irreversible, resulting in the production of distinct chemical entities, inactive or potentially toxic. Invisible and irreversible changes. Types of reactions: oxidation-reduction / photoreaction / addition reaction.

\section{Factors influencing physicochemical incompatibility reactions}

a) Concentration: The more concentrated a solution, the less stable it is.

b) PH: Avoid the contact between a two solutions with different $\mathrm{pH}$ of which one basic and the other acid under pain of observing an acid-base reaction.

c) Example: Adrenaline $(\mathrm{PH}=3)$ Aciclovir $(\mathrm{PH}=11)$

d) Contact time: This is the time that the medication takes to make the journey between the arrival in the common tubulure and the circulatory torrent. 
e) Solvents: For ph reasons, some active ingredients are incompatible with this or that solvent.

f) Other: Temperature - light.

\section{Consequences of drug incompatibility}

Physico-chemical incompatibilities between intravenous drugs lead to medical events: Local inflammatory reaction and systematic Thrombosis, sepsis, chronic vinous insufficiency, pulmonary embolism. Example According to FDA:

a) In 1994 -> calcium and phosphate salts: pulmonary emboli diffuse.

b) In 2007 -> ceftriaxone and calcium.

\section{Support}

In the literature we find tools to deal with these issues [3]:

\section{Reference works and database:}

a) Handbook on injectable drugs (trissel) with electronic form

b) Micromedex 2.0 database

c) King guide to parenteral admixtures

d) Free database stabilis 4.0

These books are made from all publications on the subject, they are intended for professionals of pharmacy.

Practical tools: The best-known example is that made by the pharmacy of the University Hospital of Geneva, among the proposed solutions is the use of color code, labeling with colors of different $\mathrm{PH}$ on the storage tags of drugs [4]:

a) Red group: drug IV with acid ph or with frequent incompatibility with blue group

b) Yellow group: IV drug with neutral ph or with frequent compatibility within the group

c) Blue group: IV drug with basic ph or frequent incompatibility with red group

d) Black group: IV medication to be administered alone

\section{Preventing drug incompatibilities}

Roles of Clinical Pharmacists: The management of drug incompatibilities is an integral part of the pharmacist's missions, which provides information on the drug because of its clinical experience in understanding the physico-chemical phenomena associated with incompatibilities.

The role of the clinical pharmacist is the management of infusions for the various vinous routes by drawing up drug compatibility tables based on data from the scientific documentation or in vitro tests that can be performed in the laboratory [5].

\section{Prevention}

Before 2 drugs come into contact with each other, it must first be ensured that they are compatible with each other. Avoid errors related to administration of injectable drugs [6].

\section{Conclusion}

The drug incompatibilities reduce the effectiveness of the treatment, it is a complex and difficult to manage problem, but it can be prevented by various ways like: The use of chart of compatibility, to use an online filter in case of risk of precipitation, use multi-lumen catheters, utilize all available pathways, limit essential drugs, IV and PO and sequencing jurisdictions.

\section{References}

1. Newton DW (2009) Drug incompatibility chemistry. Am J Health Syst Pharm 66(4): 348-357.

2. Perez M, Decaudin B, Foinard A, Barthelemy C, Debaene B, et al. (2015) Compatibility of medications during multi-infusion therapy: a controlled in vitro study on a multilumen infusion device. Anaesth Crit Care Pain Med 34(2): 83-88.

3. De Giorgi I, Guignard B, Fonzo-Christe C, Bonnabry P (2010) Evaluation of tools to prevent drug incompatibilities in paediatric and neonatal intensive care units. Pharm World Sci 32(4): 520-529.

4. Vogel Kahmann I, Bürki R, Denzler U, Höfler A, Schmid B, et al. (2003) [Incompatibility reactions in the intensive care unit. Five years after the implementation of a simple « colour code system »]. Anaesthesist 52(5): 409-412.

5. Ghaibi S, Ipema H, Gabay M (2015) ASHP guidelines on the pharmacist's role in providing drug information. Am J Health Syst Pharm 72(7): 573-577.

6. Rosenthal K (2006) Preventing IV drug incompatibilities. In: Labus DM, et al. (Eds.), IV Therapy Made Incredibly Easy. ( $3^{\text {rd }}$ edn), Lippincott Williams \& Wilkins, Philadelphia, USA. 


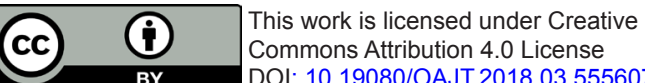

BY

DOI: 10.19080/OAJT.2018.03.555607

- Quality Editorial service

- Swift Peer Review

- Reprints availability

- E-prints Service

- Manuscript Podcast for convenient understanding

- Global attainment for your research

- Manuscript accessibility in different formats

( Pdf, E-pub, Full Text, Audio)

- Unceasing customer service

Track the below URL for one-step submission https://juniperpublishers.com/online-submission.php 